\title{
Association of plasma free fatty acids levels with the presence and severity of coronary and carotid atherosclerotic plaque in patients with type 2 diabetes mellitus
}

Ming-Hua Zhang ${ }^{1,2+}$, Ye-Xuan Cao ${ }^{1 \dagger}, \mathrm{Li}_{-}-\mathrm{Guo} \mathrm{Wu}^{2}, \mathrm{Na} \mathrm{Guo}^{2}$, Bing-Jie Hou², Li-Jing Sun², Yuan-Lin Guo', Na-Qiong Wu', Qian Dong ${ }^{1}$ and Jian-Jun $\mathrm{Li}^{1 *}$ (D)

\begin{abstract}
Background: Previous studies have suggested that patients with diabetes mellitus (DM) have higher prevalence of atherosclerotic cardiovascular disease (ASCVD), and plasma levels of free fatty acids (FFAs) are a useful marker for predicting ASCVD. We hypothesized that FFAs could predict both coronary and carotid lesions in an individual with type 2 DM (T2DM). The present study, hence, was to investigate the relation of plasma FFA level to the presence and severity of coronary and carotid atherosclerosis in patients with T2DM.

Methods: Three hundred and two consecutive individuals with T2DM who have received carotid ultrasonography and coronary angiography due to chest pain were enrolled in this study. Plasma FFAs were measured using an automatic biochemistry analyzer. Coronary and carotid severity was evaluated by Gensini score and Crouse score respectively. Subsequently, the relation of FFA levels to the presence and severity of coronary artery disease (CAD) and carotid atherosclerotic plaque (CAP) in whole individuals were also assessed.

Results: Increased plasma FFA levels were found in the groups either CAD or CAP compared to those without. Patients with higher level of FFAs had a higher CAD (89.9\%) and elevated prevalence of CAP (69.7\%). And also, patients with higher level of FFAs had a higher Gensini and Crouse scores. Multivariate regression analysis showed that FFA levels were independently associated with the presence of CAD and CAP $(O R=1.83,95 \% \mathrm{Cl}: 1.27-2.65$, $P=0.001 ; \mathrm{OR}=1.62,95 \% \mathrm{Cl}: 1.22-2.14, \mathrm{P}=0.001$, respectively). The area under the curve (AUC) was 0.68 and 0.65 for predicting the presence of CAD and CAP in patients with DM respectively.

Conclusions: The present study firstly indicated that elevated FFA levels appeared associated with both the presence and severity of CAD and CAP in patients with T2DM, suggesting that plasma FFA levels may be a useful biomarker for improving management of patients with T2DM.
\end{abstract}

Keywords: Free fatty acids, Coronary artery disease, Carotid atherosclerotic plaque, Diabetes mellitus

\footnotetext{
*Correspondence: lijianjun938@126.com; 13901010368@163.com

${ }^{+}$Ming-Hua Zhang and Ye-Xuan Cao contributed equally to this work.

'Division of Dyslipidemia, State Key Laboratory of Cardiovascular Disease, Fu

Wai Hospital, National Center for Cardiovascular Diseases, Chinese Academy

of Medical Sciences and Peking Union Medical College, No 167 BeiLiShi

Road, XiCheng District, Beijing 100037, China

Full list of author information is available at the end of the article
}

C C The Author(s). 2020 Open Access This article is licensed under a Creative Commons Attribution 4.0 International License, which permits use, sharing, adaptation, distribution and reproduction in any medium or format, as long as you give appropriate credit to the original author(s) and the source, provide a link to the Creative Commons licence, and indicate if changes were made. The images or other third party material in this article are included in the article's Creative Commons licence, unless indicated otherwise in a credit line to the material. If material is not included in the article's Creative Commons licence and your intended use is not permitted by statutory regulation or exceeds the permitted use, you will need to obtain permission directly from the copyright holder. To view a copy of this licence, visit http://creativecommons.org/licenses/by/4.0/. The Creative Commons Public Domain Dedication waiver (http://creativecommons.org/publicdomain/zero/1.0/) applies to the data made available in this article, unless otherwise stated in a credit line to the data. 


\section{Background}

Atherosclerosis (AS) is a chronic systemic disease, which is involved in multiple, large and medium-sized arteries, resulting in the different clinical phenotypes including coronary artery disease (CAD), strokes and peripheral vascular disease (PVD). Moreover, AS has also been considered as multiple cause disorder, which is associated with dyslipidemia, hypertension, smoking, overweight, and diabetes mellitus (DM) [1]. Among them, DM is named as equivalent risk fact as CAD due to its higher multiple vessel lesions in a individual.

As is well known, DM has become a major health and economic problem in both developing and developed countries, especially in China [1]. Recent data has suggested that there are one hundred and thirty million individuals with DM. More importantly, pre-diabetes mellitus (Pre-DM), an intermediate state between normal glucose regulation (NGR), is as high as $35.7 \%$ morbidity rate in China [2]. Thereby, much attention should be paid regarding the relation of risk factor to the development of DM [2].

In fact, it has been previously demonstrated that DM is a strong, independent risk factor for AS [3]. Their clinical phenotypes may clinically presented as CAD or carotid plaque. Besides, previous studies have shown that at least $30 \%$ of ischemic strokes occur in the carotid distribution area, which is a consequence of severe carotid stenosis caused by atherosclerotic occlusive disease $[4,5]$. Thereby, exploration the potential common biomarker for predicting coronary and carotid atherosclerotic plaque (CAP) would be greatly interesting clinically.

Free fatty acid (FFA), named as non-esterified fatty acid also, is a product of lipid metabolism and one of the main energy-supplying substances in the human body. It provides energy for the metabolism of heart, liver, skeletal muscle and other organs. Interestingly, previous studies including ours have indicated that elevated plasma FFA levels were related to the incidence and prognosis of $\mathrm{CAD}$, including increased risk of arrhythmia, acute myocardial infarction, sudden cardiac death and all-cause mortality [6-9]. Moreover, only two previous studies with small sample size suggested that FFA was the risk factor for carotid atherosclerosis in patients with DM $[10,11]$. In this study, we investigated the potential role of plasma FFA level in predicting the presence and severity of coronary and carotid atherosclerosis in patients with type 2 DM (T2DM).

\section{Methods}

\section{Patients}

From December 2016 to November 2018, 1026 consecutive patients with T2DM were screened out from Dyslipidemia and Cardiovascular Disease center in FuWai Hospital. The inclusion criteria for patients with T2DM were as follows: (1) men and women over 18 years old; (2) underwent coronary angiography and carotid ultrasonography. Exclusion criteria included: (1) patients whose data is not entire; (2) severe liver or/and renal insufficiency; (3) thyroid dysfunction; (4) malignant disease; (5) familial hypercholesterolemia (FH). As a result, a total of 302 eligible patients were recruited in the present study.

The study protocol was in compliance with the Declaration of Helsinki, and was approved by the hospital's ethics review committee (Fu Wai Hospital and the National Center for Cardiovascular Diseases, Beijing, China, approval number: 2013-442). Informed written consents were obtained from all patients enrolled in this study.

\section{Clinical data collection}

The clinical characteristics after admission were collected from all enrolled patients including age, gender, body mass index (BMI), the medical history of hypertension (HTN), stroke, smoking status and the usage of aspirin, statins, angiotensin converting enzyme inhibitors (ACEI), angiotensin receptor blocker (ARB) and Calcium Blocker. DM was defined by fasting plasma glucose (FPG) $\geq 7.0 \mathrm{mmol} / \mathrm{L}$ or the 2-h plasma glucose of the oral glucose tolerance test $\geq 11.1 \mathrm{mmol} / \mathrm{L}$ or currently using hypoglycemic drugs or insulin. BMI was calculated as BMI $\left(\mathrm{kg} / \mathrm{m}^{2}\right)=$ body weight $(\mathrm{kg}) /$ body height $\left(\mathrm{m}^{2}\right)$. HTN was diagnosed as a self-reported hypertension, systolic blood pressure (SBP) $\geq 140 \mathrm{mmHg}$ and/or diastolic blood pressure (DBP) $\geq 90 \mathrm{mmHg}$ for three or more consecutive times or currently taking antihypertensive drugs. Smoking was ascertained as participants who had smoked regularly within the previous 12 months. CAD was defined as coronary stenosis more than $50 \%$ of at least one coronary artery.

\section{Laboratory analysis}

Blood samples of all the enrolled patients were collected from cubital vein after a $12 \mathrm{~h}$ overnight fasting and collected into EDTA-containing tubes. Plasma concentrations of total cholesterol (TC), triglyceride (TG), highdensity lipoprotein cholesterol (HDL-C), low-density lipoprotein cholesterol (LDL-C), apolipoprotein A (apoA), apolipoprotein B (apoB), FPG and FFAs were measured using an automatic biochemistry analyzer (Hitachi 7150, Tokyo, Japan) as our previous published papers [12, 13]. Plasma hemoglobin A1C (HbA1c) levels were measured using the Tosoh G7 Automate HPLC Analyzer (TOSOH Bioscience, Japan).

\section{Coronary angiography and the coronary severity evaluation}

All enrolled patients in the present study underwent coronary angiography using standard Judkins techniques 
according to our previous studies [12, 14]. CAD was mainly manifested as coronary artery diameter stenosis of more than $50 \%$. The severity of coronary atherosclerosis was evaluated by the Gensini score, which assigned the severity score based on the degree and location of stenosis based on our previous publications [15]. In detail, the narrowing was scored as 32 for $100 \%$ occluded artery, 16 for $91-99 \%, 8$ for $76-90 \%$, 4 for $51-75 \%, 2$ for $26-50 \%$, and 1 for $1-25 \%$. The score was then multiplied by a coefficient to indicate the functional importance of each segment. The coefficient was as follows: the left main coronary artery was 5 , the proximal left anterior descending artery and the proximal circumflex artery were 2.5 , the middle left anterior descending artery was 1.5 , the right coronary artery, the distal left anterior descending artery, the posterolateral artery and obtuse artery were 1.0 , and the residual major segments were 0.5 [16]. Finally, the Gensini score was calculated by the sum of the integral of each coronary artery segment [16].

\section{Carotid ultrasound examination}

Each patient's bilateral carotid arteries were examined by two experienced ultrasound physicians who were blind to the clinical characteristics of the patients using 128 System (Acuson, Mountain View, CA, USA) with a high-resolution $7.5-10.0 \mathrm{MHz}$ transducer accrdoing to our previous study $[12,17]$. The intima-media thickness (IMT) of proximal and distal common carotid artery, bifurcation of left and right common carotid artery and carotid sinus were measured respectively. Carotid plaque was defined as the IMT exceeding $1.5 \mathrm{~mm}$, or local IMT enlargement exceeding $50 \%$ of surrounding IMT, and recorded as presence or absence. Crouse score for carotid plaques was defined as the sum of maximum thicknesses of all plaques as previously reported [18].

\section{Statistical analysis}

The values were expressed as the mean \pm standard deviation (SD) or median (Q1-Q3 quartiles) for the continuous variables and the number (percentage) for the categorical variables. The differences of parameters among groups were compared by students' $t$-test, variance analysis (ANOVA), Mann-Whitney $U$ test or Chi-square test as appropriate. Spearman's correlation coefficients were used to assess the correlations between parameters. Univariable and multivariable logistic regression analysis was performed to determine the odds ratios (ORs) and 95\% confidential intervals (CIs) of FFAs and CAD and CAP, adjusted by potential confounding factors.The diagnostic value of FFAs on the presence of CAD and CAP was analyzed by receiver operating characteristic curves (ROC). A $p$ value $<0.05$ was defined as statistically significant. The statistical analysis was performed using SPSS version 25.0 software (SPSS Inc., Chicago Illinois, USA).

\section{Results}

\section{Patient characteristics}

We divided 302 patients into CAD group and without CAD group and CAP group and without CAP group. The baseline characteristics and laboratory data of all patients were shown in Table 1. As is shown in the Table 1, the average age of the studied patients was $57.52 \pm 10.56$ years, of which $64.9 \%$ were males. The mean plasma FFA level was $0.49 \pm 0.17 \mathrm{mmol} / \mathrm{l}$.

As is shown in Table 2, the 302 patients were divided into three groups according to the tertiles of plasma level of FFAs: tertile $1(<0.41 \mathrm{mmol} / \mathrm{L}, n=107)$, tertile 2 $(0.41-0.56 \mathrm{mmol} / \mathrm{L}, n=96)$, tertile $3(>0.56 \mathrm{mmol} / \mathrm{L}, n=$ 99). Patients with the higher levels of FFAs appeared to have increased concentrations of FPG and HbA1C when compared with the first tertile (all $p$ value for trend $<0.05$ ).

\section{Relation of FFAs to CAD}

As is shown in Table 1, CAD was present in 232 patients $(76.8 \%)$ and there were more often men (70.3\%) with a higher history of HTN (76.3\%) and smoking (54.3\%). Importantly, plasma FFA levels were significantly elevated in patients with $C A D$ compared with that without $(0.51 \pm 0.17 \mathrm{mmol} / \mathrm{l}$ vs $0.41 \pm 0.15 \mathrm{mmol} / \mathrm{L}, \quad p<0.001)$. There were lower left ventricular ejection fraction (LVEF) and higher FPG, HbA1c and rates of aspirin and statins in patients with CAD (all $\mathrm{p}$ for trend $<0.05$ ). Besides, comparing the patients with low, medium and high FFA levels, we found significant differences in the prevalence of CAD and Gensini scores $(p<0.001$ in all, Table 2, Fig. 1a and b).

In addition, the results showed that FFAs were positively associated with CAD presence $(r=0.257, \mathrm{p}<0.001)$ and Gensini scores $(r=0.268, p<0.001)$ in the Spearman correlation analysis (Table 3). Moreover, statin therapy, FPG and $\mathrm{HbA1c}$ were positively associated with the presence of CAD and Gensini scores. In the multivariable model (Table 4), FFA per SD increase was associated with increased risk of the presence of $\mathrm{CAD}(\mathrm{OR}=1.83,95 \% \mathrm{CI}$ : $1.27-2.65, p=0.001$ ) after adjusting traditional risk factors including age, gender, BMI, statin therapy, HTN, smoking, FPG, HbA1C, TC, HDL-C and LDL-C. Besides, gender, HTN, statin therapy and HbAlc were also predictors for the presence of CAD.

\section{Association of FFAs with CAP}

The data from Table 1 indicated that patients with CAP were older $(59.10 \pm 11.01$ vs $55.61 \pm 9.70, p=0.004)$, more often male (68.5\%) and had higher rate of HTN (77.0\%). Plasma FFA levels were significantly elevated in 
Table 1 Baseline characteristics in patients with or without CAD and CAP

\begin{tabular}{|c|c|c|c|c|c|c|c|}
\hline Variables & $\begin{array}{l}\text { Total } \\
(n=302)\end{array}$ & $\begin{array}{l}\text { CAD } \\
(n=232)\end{array}$ & $\begin{array}{l}\text { Non-CAD } \\
(n=70)\end{array}$ & $P$ value & $\begin{array}{l}\text { CAP } \\
(n=165)\end{array}$ & $\begin{array}{l}\text { Non-CAP } \\
(n=137)\end{array}$ & $P$ value \\
\hline \multicolumn{8}{|l|}{ Baseline characteristics } \\
\hline Age, years & $57.52 \pm 10.56$ & $58.08 \pm 10.48$ & $55.66 \pm 10.72$ & 0.093 & $59.10 \pm 11.01$ & $55.61 \pm 9.70$ & 0.004 \\
\hline Male, n (\%) & $196(64.9)$ & $163(70.3)$ & $33(47.1)$ & $<0.001$ & $113(68.5)$ & $83(60.6)$ & 0.152 \\
\hline $\mathrm{BMI}, \mathrm{kg} / \mathrm{m}^{2}$ & $26.43 \pm 3.15$ & $26.36 \pm 3.07$ & $26.57 \pm 3.41$ & 0.648 & $26.32 \pm 3.11$ & $26.51 \pm 3.20$ & 0.606 \\
\hline Family history of CAD, $\mathrm{n}(\%)$ & $42(13.9)$ & $32(13.8)$ & $10(14.3)$ & 0.855 & $22(13.3)$ & 20(14.6) & 0.758 \\
\hline HTN, n (\%) & $217(71.9)$ & $177(76.3)$ & $40(57.1)$ & 0.002 & $127(77.0)$ & $90(65.7)$ & 0.030 \\
\hline Stroke, n (\%) & $17(5.6)$ & $12(5.2)$ & $5(7.1)$ & 0.519 & $12(7.3)$ & $5(3.6)$ & 0.192 \\
\hline Smoking, n (\%) & $154(51.0)$ & $126(54.3)$ & $28(40.0)$ & 0.028 & $91(55.2)$ & $63(46.0)$ & 0.129 \\
\hline Alcohol drinker, n(\%) & $102(33.8)$ & $80(34.5)$ & $22(31.4)$ & 0.557 & $63(38.2)$ & $39(28.5)$ & 0.085 \\
\hline \multicolumn{8}{|l|}{ Laboratory parameters } \\
\hline $\mathrm{FPG}, \mathrm{mmol} / \mathrm{L}$ & $7.42 \pm 2.16$ & $7.63 \pm 2.27$ & $6.68 \pm 1.54$ & $<0.001$ & $7.57 \pm 2.20$ & $7.24 \pm 2.11$ & 0.185 \\
\hline $\mathrm{HbA1c}(\%)$ & $7.33 \pm 1.32$ & $7.49 \pm 1.36$ & $6.77 \pm 0.98$ & $<0.001$ & $7.41 \pm 1.29$ & $7.24 \pm 1.35$ & 0.289 \\
\hline $\mathrm{TC}, \mathrm{mmol} / \mathrm{L}$ & $4.29 \pm 1.29$ & $4.21 \pm 1.32$ & $4.55 \pm 1.16$ & 0.056 & $4.39 \pm 1.45$ & $4.17 \pm 1.06$ & 0.127 \\
\hline $\mathrm{LDL}-\mathrm{C}, \mathrm{mmol} / \mathrm{L}$ & $2.61 \pm 1.10$ & $2.55 \pm 1.13$ & $2.83 \pm 0.99$ & 0.066 & $2.70 \pm 1.26$ & $2.51 \pm 0.86$ & 0.114 \\
\hline $\mathrm{HDL}-\mathrm{C}, \mathrm{mmol} / \mathrm{L}$ & $1.02 \pm 0.28$ & $1.01 \pm 0.29$ & $1.03 \pm 0.26$ & 0.697 & $1.03 \pm 0.29$ & $1.00 \pm 0.26$ & 0.315 \\
\hline $\mathrm{TG}, \mathrm{mmol} / \mathrm{L}$ & $1.64(1.25-2.41)$ & $1.62(1.22-2.39)$ & $1.93(1.31-2.63)$ & 0.211 & $1.69(1.21-2.58)$ & $1.58(1.29-2.37)$ & 0.854 \\
\hline ApoA, g/L & $1.33 \pm 0.43$ & $1.33 \pm 0.47$ & $1.37 \pm 0.26$ & 0.481 & $1.37 \pm 0.52$ & $1.29 \pm 0.28$ & 0.131 \\
\hline ApoB, g/L & $0.90 \pm 0.30$ & $0.88 \pm 0.30$ & $0.94 \pm 0.29$ & 0.168 & $0.89 \pm 0.32$ & $0.91 \pm 0.27$ & 0.52 \\
\hline $\mathrm{Lp}(\mathrm{a}), \mathrm{mg} / \mathrm{dL}$ & $\begin{array}{l}115.34 \\
(53.68-281.85)\end{array}$ & $\begin{array}{l}112.35 \\
(53.9-299.98)\end{array}$ & $\begin{array}{l}122.1 \\
(52.95-231.38)\end{array}$ & 0.933 & $\begin{array}{l}110.1 \\
(60.25-253.0)\end{array}$ & $\begin{array}{l}125.7 \\
(45.1-334.6)\end{array}$ & 0.622 \\
\hline $\mathrm{Hs}-\mathrm{CRP}, \mathrm{mg} / \mathrm{dL}$ & $1.45(0.77-2.78)$ & $1.46(0.77-2.73)$ & $1.39(0.69-2.87)$ & 0.824 & $1.51(0.87-2.87)$ & $1.37(0.61-2.65)$ & 0.289 \\
\hline LVEF (\%) & $63.23 \pm 7.44$ & $62.67 \pm 7.92$ & $65.04 \pm 5.23$ & 0.021 & $62.64 \pm 7.69$ & $63.91 \pm 7.10$ & 0.147 \\
\hline $\mathrm{FFAs}, \mathrm{mmol} / \mathrm{L}$ & $0.49 \pm 0.17$ & $0.51 \pm 0.17$ & $0.41 \pm 0.15$ & $<0.001$ & $0.54 \pm 0.17$ & $0.44 \pm 0.15$ & $<0.001$ \\
\hline \multicolumn{8}{|l|}{ Medicines } \\
\hline Aspirin, n (\%) & 177 (58.6) & $154(66.4)$ & $23(32.9)$ & 0.002 & $92(55.8)$ & $85(62.0)$ & 0.147 \\
\hline Statin, n (\%) & $145(48.0)$ & $122(52.6)$ & $23(32.9)$ & 0.004 & $81(49.1)$ & $64(46.7)$ & 0.681 \\
\hline ACEI, n (\%) & $34(11.3)$ & $32(13.8)$ & $2(2.9)$ & 0.071 & $20(12.1)$ & $14(10.2)$ & 0.524 \\
\hline ARB, n (\%) & 44 (14.6) & 36 (15.5) & $8(11.4)$ & 0.652 & $24(14.5)$ & $20(14.6)$ & 0.824 \\
\hline Calcium Blocker, n (\%) & $60(19.9)$ & $48(20.7)$ & $12(17.1)$ & 0.390 & 31 (18.8) & $29(21.2)$ & 0.764 \\
\hline
\end{tabular}

Data are expressed as mean $\pm S D$, median (25th-75th percentile) or $\mathrm{n}(\%)$.Bold values indicate statistical significance. CAD coronary artery disease, CAP carotid atherosclerotic plaque, BMI body mass index, HTN hypertension, $F P G$ fasting plasma glucose, HbA1C hemoglobin A1C, TC total cholesterol, $L D L-C$ LDL cholesterol, HDL-C HDL cholesterol, TG triglyceride, L $L(a)$ lipoprotein(a), Hs-CRP high sensitivity C-reactive protein, LVEF left ventricular ejection fraction, $F F A s$ free fatty acids, $A C E l$ angiotensin converting enzyme inhibitors, $A R B$ angiotensin receptor blocker

patients with CAP compared with that without $(0.54 \pm$ $0.17 \mathrm{mmol} / \mathrm{l}$ vs $0.44 \pm 0.15 \mathrm{mmol} / \mathrm{L}, p<0.001)$. We also compared the patients with low, medium and high FFA levels and found significant differences in the prevalence of CAP and Crouse scores (all $p$ value $<0.001$; Table 2, Fig. 1c and d).

Moreover, spearman correlation analysis (Table 3) showed that FFAs were positively correlated with the presence of CAP $(r=0.254, p<0.001)$ and Crouse scores $(\mathrm{r}=0.359, \mathrm{p}<0.001)$. Additionally, data suggested that age and FPG were positively correlated with Crouse scores. After adjusting traditional risk factors including age, gender, BMI, statin therapy, HTN, smoking, FPG,
HbA1C, TC, HDL-C and LDL-C, FFA per SD increase was associated with increased risk of the presence of CAP in multivariable regression analysis $(\mathrm{OR}=1.62$, 95\%CI: 1.22-2.14, $p=0.001$, Table 4). Besides, age and gender were also predictors for the presence of CAP.

\section{Diagnostic value of FFAs on CAD and CAP}

As is shown in Fig. 2 a and b, the area under the curve (AUC) indicated that the FFAs had an appropriate discriminate ability in diagnosing the presence of $C A D$ (AUC $=0.68,95 \%$ CI: $0.61-0.75, p<0.001$ ) and CAP (AUC $=0.65,95 \%$ CI: $0.59-0.71, \mathrm{p}<0.001$ ) in patients with T2DM. 
Table 2 Demographic characteristics stratified by FFAs tertiles (mmol/L)

\begin{tabular}{|c|c|c|c|c|}
\hline Variables & $\begin{array}{l}\text { Tertile } 1 \\
(<0.41) \\
N=107\end{array}$ & $\begin{array}{l}\text { Tertile } 2 \\
(0.41-0.56)\end{array}$ & $\begin{array}{l}\text { Tertile } 3 \\
(>0.56)\end{array}$ & $P$-value \\
\hline \multicolumn{5}{|l|}{ Baseline characteristics } \\
\hline Age, years & $57.19 \pm 9.27$ & $55.81 \pm 12.01$ & $59.53 \pm 10.17$ & 0.045 \\
\hline Male, n (\%) & $65(60.7)$ & $67(69.8)$ & $64(64.6)$ & 0.402 \\
\hline $\mathrm{BMI}, \mathrm{kg} / \mathrm{m}^{2}$ & $26.09 \pm 3.03$ & $27.00 \pm 3.42$ & $26.20 \pm 2.95$ & 0.092 \\
\hline Family history of CAD, n (\%) & $14(13.1)$ & 18(18.8) & 10(10.1) & 0.173 \\
\hline HTN, n (\%) & $76(71.0)$ & $66(68.8)$ & 75(75.8) & 0.538 \\
\hline$C A D, n(\%)$ & $71(66.4)$ & $72(75.0)$ & 89(89.9) & $<0.001$ \\
\hline Stroke, n (\%) & $6(5.6)$ & $5(5.2)$ & $6(6.1)$ & 0.972 \\
\hline Smoking, n (\%) & $53(49.5)$ & $54(56.3)$ & $47(47.5)$ & 0.516 \\
\hline Alcohol drinker, n (\%) & $36(33.6)$ & $33(34.4)$ & 33(33.3) & 0.993 \\
\hline Carotid plaque, n (\%) & $43(40.2)$ & $53(55.2)$ & $69(69.7)$ & $<0.001$ \\
\hline \multicolumn{5}{|l|}{ Laboratory parameters } \\
\hline $\mathrm{FPG}, \mathrm{mmol} / \mathrm{L}$ & $6.89 \pm 1.96$ & $7.57 \pm 2.01$ & $7.84 \pm 2.40$ & 0.005 \\
\hline HbA1c (\%) & $7.15 \pm 1.21$ & $7.21 \pm 1.34$ & $7.63 \pm 1.36$ & 0.022 \\
\hline $\mathrm{TC}, \mathrm{mmol} / \mathrm{L}$ & $4.20 \pm 1.19$ & $4.13 \pm 1.31$ & $4.54 \pm 1.35$ & 0.060 \\
\hline LDL-C, mmol/L & $2.55 \pm 0.97$ & $2.56 \pm 1.13$ & $2.72 \pm 1.20$ & 0.469 \\
\hline $\mathrm{HDL}-\mathrm{C}, \mathrm{mmol} / \mathrm{L}$ & $1.00 \pm 0.28$ & $0.99 \pm 0.27$ & $1.07 \pm 0.29$ & 0.097 \\
\hline $\mathrm{TG}, \mathrm{mmol} / \mathrm{L}$ & $1.46(1.27-2.21)$ & $1.63(1.25-2.36)$ & $1.82(1.20-2.88)$ & 0.127 \\
\hline ApoA, g/L & $1.29 \pm 0.24$ & $1.35 \pm 0.67$ & $1.38 \pm 0.25$ & 0.295 \\
\hline ApoB, g/L & $0.90 \pm 0.30$ & $0.88 \pm 0.30$ & $0.91 \pm 0.29$ & 0.697 \\
\hline $\mathrm{Lp}(\mathrm{a}), \mathrm{mg} / \mathrm{dL}$ & $116.75(51.55-354.49)$ & $156.4(60.33-316.70)$ & $95.3(52.70-214.20)$ & 0.121 \\
\hline $\mathrm{Hs}-\mathrm{CRP}, \mathrm{mg} / \mathrm{dL}$ & $1.28(0.63-2.82)$ & $1.47(0.84-2.98)$ & $1.58(0.82-2.50)$ & 0.509 \\
\hline FFAs, $\mathrm{mmol} / \mathrm{L}$ & $0.32 \pm 0.07$ & $0.49 \pm 0.04$ & $0.68 \pm 0.11$ & $<0.001$ \\
\hline Gensini score & 19.0(8.0-41.5) & $30.0(8.0-64.0)$ & $46.0(16.0-86.0)$ & $<0.001$ \\
\hline Crouse score & $2.40 \pm 1.47$ & $3.02 \pm 1.55$ & $3.34 \pm 1.73$ & $<0.001$ \\
\hline \multicolumn{5}{|l|}{ Medicines } \\
\hline Aspirin, n (\%) & $56(52.3)$ & $56(58.3)$ & $65(65.7)$ & 0.496 \\
\hline Statin, n (\%) & $48(44.9)$ & $48(50.0)$ & $49(49.5)$ & 0.717 \\
\hline ACEI, n (\%) & $11(10.3)$ & 15(15.6) & $8(8.1)$ & 0.278 \\
\hline ARB, n (\%) & $17(15.9)$ & 15(15.6) & $12(12.1)$ & 0.519 \\
\hline Calcium Blocker, n (\%) & 21(19.6) & 19(19.8) & $20(20.2)$ & 0.956 \\
\hline
\end{tabular}

Data are expressed as mean $\pm S D$, median (25th-75th percentile) or $\mathrm{n}(\%)$. Bold values indicate statistical significance. BMI body mass index, HTN hypertension, CAD coronary artery disease, FPG fasting plasma glucose, HbA1C hemoglobin A1C, TC total cholesterol, $L D L-C$ LDL cholesterol, HDL-C HDL cholesterol, TG triglyceride, $L p(a)$ lipoprotein(a), $H s-C R P$ high sensitivity C-reactive protein, $F F A s$ free fatty acid, $A C E l$ angiotensin converting enzyme inhibitors, $A R B$ angiotensin receptor blocker

\section{Discussion}

Compared with what we have known about the role of FFAs in the presence, severity, and clinical outcomes in patients with CAD, less is known in the predicting value of FFAs in different sites of AS. In another word, the value of FFAs for predicting atherosclerotic cardiovascular disease (ASCVD) in T2DM has been less investigated, especially in the presence and severity of CAD and CAP. In the present study, we consecutively enrolled 302 patients with T2DM who underwent coronary angiography and carotid ultrasonography for the purpose of examining the relationship between FFAs and the presence and severity of CAD and CAP. The major novel findings were as follows: 1) the patients with CAD and CAP had higher FFA levels; 2) plasma FFA level was independently associated with the presence of both CAD and CAP after adjustment for traditional risk factors. These finding might improve our understandings regarding the association of FFAs with AS. 


\section{A}
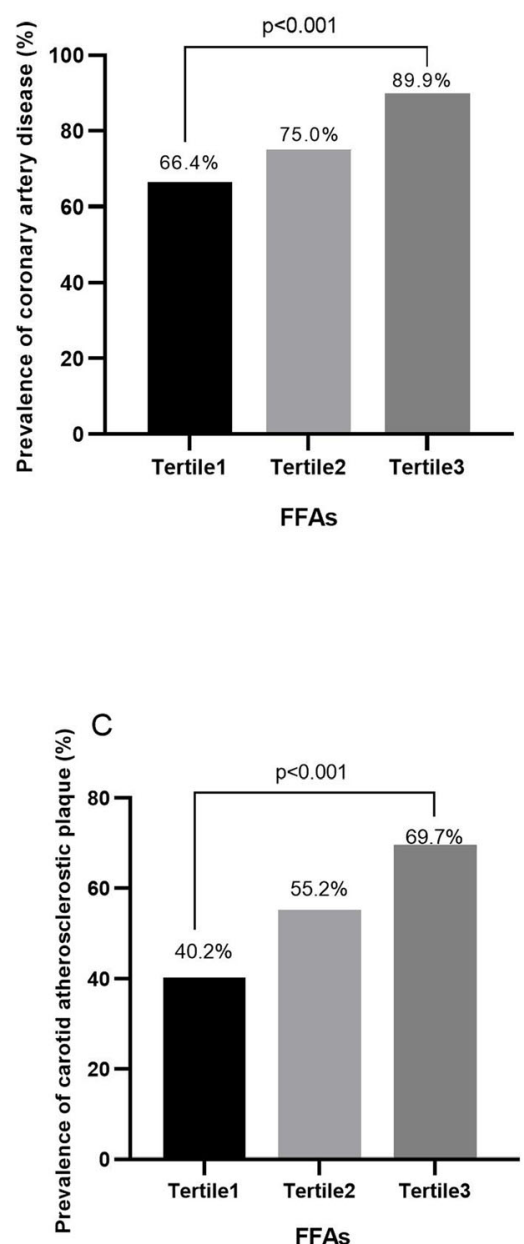

B

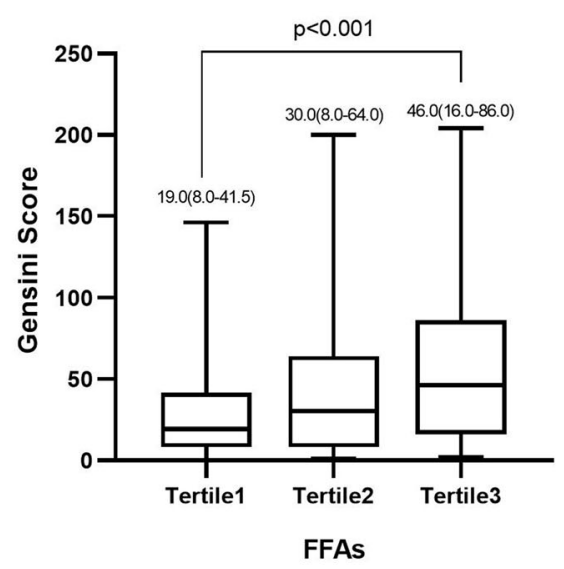

D

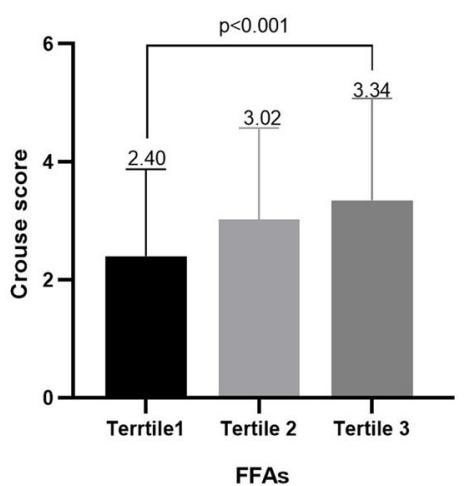

Fig. 1 Association between free fatty acids and the presence and severity of coronary artery disease and carotid atherosclerotic plaque

Although FFAs have been found for many years, it still have important significance for clinical diagnosis and prognosis of metabolic diseases. According to previous studies, FFAs play an important role in cell membrane formation, cell signal transduction and regulation of glucose metabolism [19, 20]. Moreover, recent accumulated evidence has confirmed that FFAs were involved in the pathogenesis of insulin resistance and subsequent development of metabolic syndrome such as obesity and T2DM [21]. Subsequent studies further suggested that excess of plasma FFAs can induce oxidative stress, inflammation and vascular endothelial cell damage [22-24], which leads to accelerated rupture of atherosclerotic plaque and disease progression. In addition, elevated plasma FFAs also contributed to HDL dysfunction based on the fact that they increased the concentration of TG in HDL particles, which is considered to be a factor affecting AS [25].
In fact, previous studies have also indicated that FFAs is a useful marker for predicting the presence and severity of several cardiovascular diseases, particularly in CAD. Stefan [7] et al. have proved the independent association of FFAs with all-cause and cardiovascular mortality in 2567 patients with CAD for 5.38 years follow-up. Olga [26] et al. have enrolled 79 patients with ST elevation myocardial infarction and found that FFAs were associated with a higher risk of myocardial infarction and acute heart failure. Moreover, Taniguchi et al. [10, 11] have revealed the association of serum non-esterified fatty acids with carotid atherosclerosis (IMT in plaquefree segments and carotid stenosis in plaque segments) in 54 non-obese, non-hypertensive, well-controlled Japanese patients with T2DM. However, there is no data available regarding the relationship between plasma FFAs and the presence and severity of CAD and CAP in an individual with T2DM. That is the reason why we performed the present study. 
Table 3 Correlation between risk factors and the presence and severity of coronary artery disease and carotid atherosclerotic plaque

\begin{tabular}{|c|c|c|c|c|c|c|c|c|}
\hline \multirow[t]{2}{*}{ Variables } & \multicolumn{2}{|l|}{ CAD } & \multicolumn{2}{|c|}{ Gensini score } & \multicolumn{2}{|c|}{ Carotid plaque } & \multicolumn{2}{|c|}{ Crouse score } \\
\hline & $r$ & $\overline{p \text {-value }}$ & $r$ & $\overline{p \text {-value }}$ & $r$ & $\overline{p \text {-value }}$ & $r$ & $\overline{p \text {-value }}$ \\
\hline Age,year & 0.113 & 0.050 & 0.112 & 0.067 & 0.149 & 0.009 & 0.144 & 0.012 \\
\hline Male, n(\%) & -0.204 & $<0.001$ & -0.068 & 0.265 & -0.082 & 0.153 & -0.090 & 0.118 \\
\hline BMl, kg/m 2 & -0.017 & 0.780 & -0.046 & 0.461 & -0.016 & 0.784 & 0.007 & 0.906 \\
\hline Smoking, n(\%) & -0.127 & 0.028 & -0.045 & 0.469 & -0.088 & 0.130 & -0.085 & 0.144 \\
\hline Statin, n(\%) & -0.167 & 0.004 & -0.133 & 0.029 & -0.024 & 0.682 & -0.014 & 0.802 \\
\hline $\mathrm{FPG}, \mathrm{mmol} / \mathrm{L}$ & 0.184 & 0.001 & 0.129 & 0.035 & 0.079 & 0.173 & 0.117 & 0.044 \\
\hline $\mathrm{HbA1c}(\%)$ & 0.247 & $<0.001$ & 0.189 & 0.002 & 0.073 & 0.211 & 0.049 & 0.399 \\
\hline $\mathrm{TC}, \mathrm{mmol} / \mathrm{L}$ & -0.111 & 0.056 & -0.100 & 0.102 & 0.060 & 0.297 & 0.024 & 0.675 \\
\hline $\mathrm{LDL}-\mathrm{C}, \mathrm{mmol} / \mathrm{L}$ & -0.106 & 0.066 & -0.087 & 0.157 & 0.048 & 0.412 & 0.060 & 0.300 \\
\hline $\mathrm{Lpa}, \mathrm{mg} / \mathrm{dl}$ & 0.005 & 0.933 & 0.049 & 0.421 & -0.029 & 0.622 & -0.020 & 0.727 \\
\hline $\mathrm{Hs}-\mathrm{CRP}, \mathrm{mg} / \mathrm{l}$ & 0.013 & 0.825 & 0.060 & 0.327 & 0.061 & 0.290 & 0.106 & 0.066 \\
\hline $\mathrm{FFAs}, \mathrm{mmol} / \mathrm{L}$ & 0.257 & $<0.001$ & 0.268 & $<0.001$ & 0.254 & $<0.001$ & 0.359 & $<0.001$ \\
\hline
\end{tabular}

Bold values indicate statistical significance. BMI body mass index, FPG fasting plasma glucose, HbA1C hemoglobin A1C, TC total cholesterol, $L D L-C$ LDL cholesterol, $L p(a)$ lipoprotein(a), Hs-CRP high sensitivity C-reactive protein, FFAs free fatty acids

Interestingly, we found that the patients with CAD and CAP had nearly more that $20 \%$ increase in plasma FFA levels (CAD:0.51 $\pm 0.17 \mathrm{mmol} / \mathrm{L} \quad$ vs $0.41 \pm 0.15$ $\mathrm{mmol} / \mathrm{L}$, CAP: $0.54 \pm 0.17 \mathrm{mmol} / \mathrm{L}$ vs $0.44 \pm 0.15 \mathrm{mmol} /$ $\mathrm{L}$, respectively). In addition, we used Gensini and Crouse scores to examine the relation of FFAs to the severity of CAD and CAP. We found that the significantly correlations between Gensini and Crouse scores and FFA levels and patients with higher plasma FFA levels had higher Gensini and Crouse scores. Finally, this study confirmed that FFAs were independently associated with the presence of CAD and CAP in patients with DM after adjusting for confounding risk factors.
The clinical implication of the present study was that the FFAs might be involved in not only CAD but also CAP in patients with T2DM. Therefore, the data in this study provided additional clues for developing more effective secondary prevention and treatment strategies for the patients with T2DM. Furthermore, in view of fact that the measurement of plasma FFA levels is convenient and cost-effective, it is better to be commonly measured in diabetic patients with CAD or high risk for cardiovascular disease, which is helpful to disease stratification and treatment in clinical practice.

Although the present provided additional information concerning the relationship between FFAs and multiple

Table 4 Univariate and multivariate analysis for the association between FFAs and the presence of coronary artery disease and carotid atherosclerotic plaque

\begin{tabular}{|c|c|c|c|c|c|c|c|c|}
\hline \multirow[t]{2}{*}{ Variables } & \multicolumn{2}{|l|}{ Univariate $^{a}$} & \multicolumn{2}{|l|}{ Multivariate $^{a}$} & \multicolumn{2}{|l|}{ Univariate $^{b}$} & \multicolumn{2}{|l|}{ Multivariate $^{b}$} \\
\hline & OR $(95 \% \mathrm{Cl})$ & $\overline{P \text {-value }}$ & OR $(95 \% \mathrm{Cl})$ & $\overline{P \text {-value }}$ & OR $(95 \% \mathrm{Cl})$ & $\overline{P \text {-value }}$ & OR $(95 \% \mathrm{Cl})$ & P-value \\
\hline$\overline{\text { Age }}$ & $1.03(1.00-1.07)$ & 0.129 & $1.04(1.00-1.07)$ & 0.063 & $1.05(1.02-1.08)$ & 0.003 & $1.04(1.02-1.07)$ & 0.003 \\
\hline Gender & $3.78(1.51-9.46)$ & 0.004 & $3.91(1.89-8.01)$ & $<0.001$ & $1.79(0.87-3.68)$ & 0.114 & $1.87(1.06-3.31)$ & 0.032 \\
\hline HTN & $2.31(1.17-4.62)$ & 0.016 & $2.12(1.01-4.13)$ & 0.027 & $1.71(0.96-3.03)$ & 0.068 & $1.67(0.96-2.91)$ & 0.072 \\
\hline Smoking & $0.84(0.37-1.86)$ & 0.66 & & & $1.22(0.64-2.31)$ & 0.545 & & \\
\hline Statin & $1.92(0.95-3.88)$ & 0.069 & $2.12(1.11-4.07)$ & 0.024 & $0.92(0.54-1.59)$ & 0.772 & & \\
\hline $\mathrm{BMl}$ & $0.94(0.85-1.04)$ & 0.237 & & & $0.99(0.91-1.08)$ & 0.740 & & \\
\hline FPG & $1.12(0.92-1.38)$ & 0.266 & & & $1.01(0.88-1.16)$ & 0.859 & & \\
\hline $\mathrm{HbA} 1 \mathrm{C}$ & $1.55(1.01-2.17)$ & 0.013 & $1.70(1.25-2.30)$ & 0.001 & 1.04(0.83-1.30) & 0.729 & & \\
\hline $\mathrm{TC}$ & $0.89(0.49-1.61)$ & 0.705 & & & $1.04(0.65-1.65)$ & 0.879 & & \\
\hline $\mathrm{HDL}-\mathrm{C}$ & $0.78(0.22-2.72)$ & 0.691 & & & $0.97(0.35-2.74)$ & 0.958 & & \\
\hline LDL-C & $0.96(0.50-1.85)$ & 0.908 & & & $1.14(0.68-1.92)$ & 0.611 & & \\
\hline FFAs per SD & $1.89(1.29-2.77)$ & 0.001 & $1.83(1.27-2.65)$ & 0.001 & $1.60(1.20-2.14)$ & 0.002 & $1.62(1.22-2.14)$ & 0.001 \\
\hline
\end{tabular}

${ }^{\mathrm{a}}$ coronary artery disease; ${ }^{\mathrm{b}}$ carotid atherosclerotic plaque; OR odds ratio, $C l$ confidence interval, $H T N$ hypertension, $B M I$ body mass index, FPG fasting plasma glucose, HbA1C hemoglobin A1C, TC total cholesterol, HDL-C HDL cholesterol, LDL- C LDL cholesterol, FFAs free fatty acids 

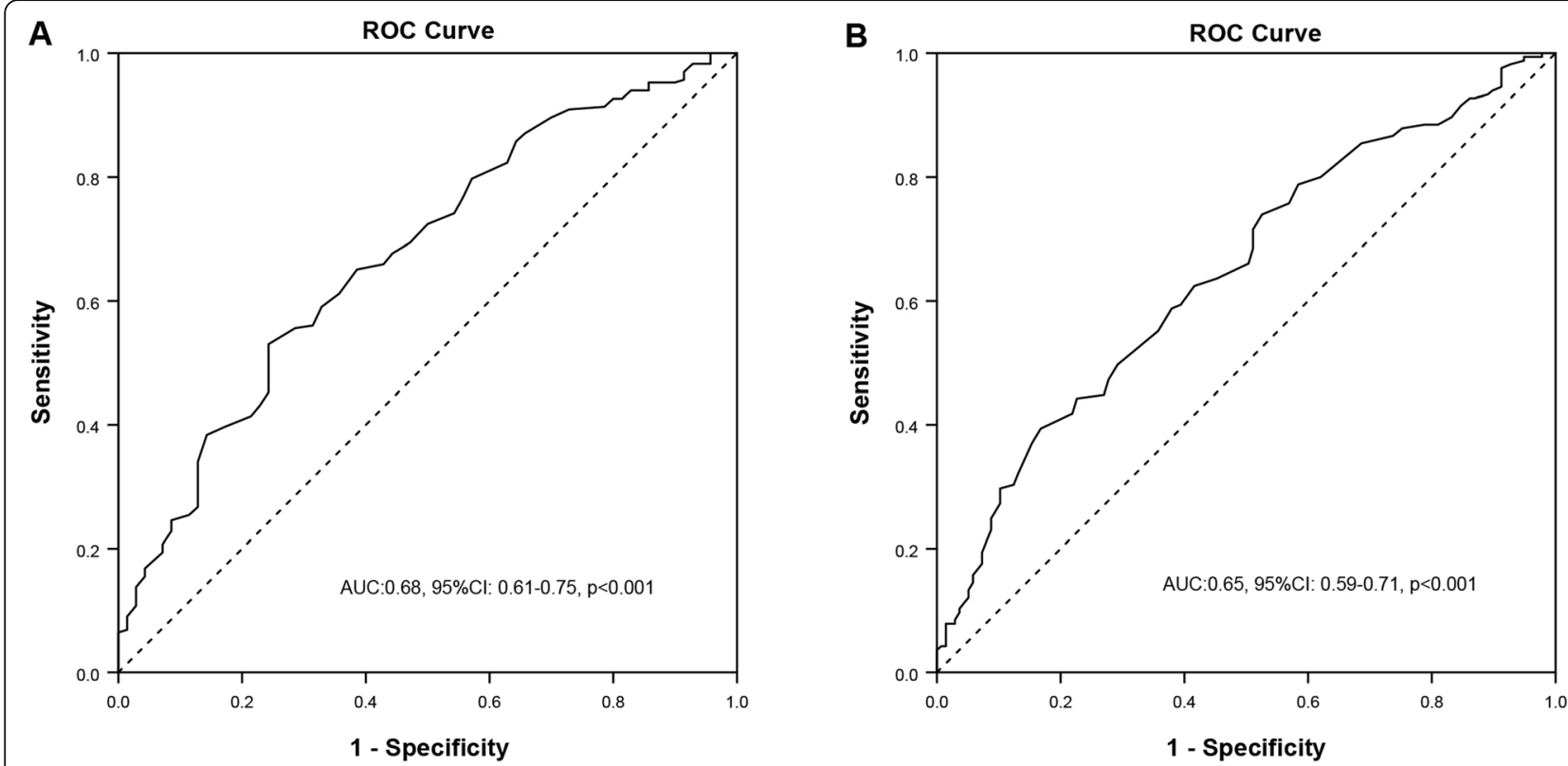

Fig. 2 The area under the curve of free fatty acids in predicting the presence of coronary artery disease (a) and carotid atherosclerotic plaque (b). AUC: area under the curve; ROC: receiver operating characteristics.

site of AS, there were several limitations in our study. Firstly, this is a single center study with small sample size, which may lead to potential selection bias. Moreover, because the concentration of FFAs in blood is affected by nutritional status, physical activity and disease cycle, and the change of plasma FFA level with the development of diabetes is not clear, it may not be able to accurately reflect the change of FFAs in blood by one measurement. Finally, we did not perform follow-up and correlation analysis of final events in our study. Therefore, further study with large sample size may be needed to confirm our findings.

\section{Conclusions}

In conclusion, data from our study verified that elevated FFA levels appeared associated with both the presence and severity of CAD and CAP in patients with T2DM, suggesting that plasma FFA levels may be a useful biomarker for improving management of patients with T2DM.

\section{Abbreviations}

FFAs: Free fatty acids; T2DM: Type 2 diabetes mellitus; CAD: Coronary artery disease; AS: Atherosclerosis; ASCVD: Atherosclerotic cardiovascular disease;

CAP: Carotid atherosclerotic plaque; BMI: Body mass index;

HTN: Hypertension; ACEl: Angiotensin converting enzyme inhibitors;

ARB: Angiotensin receptor blocker; FPG: Fasting plasma glucose; TC: Total

cholesterol; TG: Triglyceride; HDL-C: high-density lipoprotein cholesterol; LDL-

C: low-density lipoprotein cholesterol; apoA: Apolipoprotein A;

apoB: Apolipoprotein B; HbA1c: Hemoglobin A1C; IMT: Intima-media

thickness; LVEF: Left ventricular ejection fraction

\section{Acknowledgments}

The authors thank all the staff and participants of this study for their important contributions.

\section{Authors' contributions}

Zhang $\mathrm{M}-\mathrm{H}$ and $\mathrm{Cao} \mathrm{Y}-\mathrm{X}$ completed the project and analyzed the data. Zhang $\mathrm{M}$-H wrote the manuscript. Li J-J designed the study, interpreted the data, and contributed to critically revising the article. Wu L-G, Guo N, Hou BJ, Sun L-J, Guo Y-L, Wu N-Q and Dong Q contributed to data collection and procedure of laboratory examination. All authors have approved the final article.

\section{Funding}

This study was partly supported by Capital Health Development Fund (201614035) and Chinese Academy of Medical Sciences Innovation Fund for Medical Sciences (2016-12M-1-011) awarded to Dr. Jian-Jun Li, MD, PhD. The funding bodies played no role in the design of the study and collection, analysis, and interpretation of data and in writing the manuscript.

\section{Availability of data and materials}

The datasets used and/or analysed during the current study are not publicly available but are available from the corresponding author on reasonable request.

\section{Ethics approval and consent to participate}

This protocol of the present study was in compliance with the Declaration of Helsinki, and was approved by the hospital's ethics review committee (Fu Wai Hospital and the National Center for Cardiovascular Diseases, Beijing, China). Informed written consents were obtained from all patients enrolled in this study.

Consent for publication

Not applicable.

Competing interests

The authors declare that they have no competing interests. 


\section{Author details}

'Division of Dyslipidemia, State Key Laboratory of Cardiovascular Disease, Fu Wai Hospital, National Center for Cardiovascular Diseases, Chinese Academy of Medical Sciences and Peking Union Medical College, No 167 BeiLiShi Road, XiCheng District, Beijing 100037, China. ${ }^{2}$ Department of Internal Medicine, The People's Hospital of Tang Xian County, Baoding 072350, Hebei, China.

Received: 13 March 2020 Accepted: 13 October 2020

Published online: 21 October 2020

\section{References}

1. Shaw JE, Sicree RA, Zimmet PZ. Global estimates of the prevalence of diabetes for 2010 and 2030. Diabetes Res Clin Pract. 2010;87:4-14.

2. Jin JL, Cao YX, Zhang HW, Sun D, Hua Q, Li YF, Guo YL, Wu NQ, Zhu CG, Gao Y, et al. Lipoprotein(a) and cardiovascular outcomes in patients with coronary artery disease and Prediabetes or diabetes. Diabetes Care. 2019;42: 1312-8.

3. Ergul A, Kelly-Cobbs A, Abdalla M, Fagan SC. Cerebrovascular complications of diabetes: focus on stroke. Endocr Metab Immune Disord Drug Targets. 2012;12:148-58.

4. Kuebler TW, Bendick PJ, Fineberg SE, Markand ON, Norton JA Jr, Vinicor FN, Clark CM Jr. Diabetes mellitus and cerebrovascular disease: prevalence of carotid artery occlusive disease and associated risk factors in 482 adult diabetic patients. Diabetes Care. 1983;6:274-8.

5. Fisher M, Martin A, Cosgrove M, Norris JW, The NASCET-ACAS plaque project. North American Symptomatic Carotid Endarterectomy Trial. Asymptomatic Carotid Atherosclerosis Study. Stroke. 1993;24:124-5 discussion $131-2$

6. Roy VK, Kumar A, Joshi P, Arora J, Ahanger AM. Plasma free fatty acid concentrations as a marker for acute myocardial infarction. J Clin Diagn Res. 2013;7:2432-4.

7. Pilz S, Scharnagl H, Tiran B, Seelhorst U, Wellnitz B, Boehm BO, Schaefer JR Marz W. Free fatty acids are independently associated with all-cause and cardiovascular mortality in subjects with coronary artery disease. J Clin Endocrinol Metab. 2006;91:2542-7.

8. Tansey MJ, Opie LH. Relation between plasma free fatty acids and arrhythmias within the first twelve hours of acute myocardial infarction. Lancet. 1983;2:419-22.

9. Oliver MF, Kurien VA, Greenwood TW. Relation between serum-free-fatty acids and arrhythmias and death after acute myocardial infarction. Lancet. 1968;: 1:710-4.

10. Taniguchi A, Nakai Y, Fukushima M, Teramura S, Hayashi R, Hama K, Marumoto K, Watanabe T, Yoshioka I, Sakaguchi K, et al. Ultrasonographically assessed carotid atherosclerosis in Japanese type 2 diabetic patients: role of nonesterified fatty acids. Metab Clin Exp. 2002;51: 539-43.

11. Taniguchi A, Sakai M, Teramura S, Fukushima M, Hama K, Marumoto K, Nezumi N, Yoshida T, Nagasaka S, Hayashi R, et al. Serum nonesterified fatty acids are related with carotid atherosclerotic plaque in nonobese nonhypertensive Japanese type 2 diabetic patients. Diabetes Care. 2001;24: $1505-7$

12. Sun D, Zhou BY, Zhao X, Li S, Zhu CG, Guo YL, Gao Y, Wu NQ, Liu G, Dong $\mathrm{Q}$, et al. Lipoprotein(a) level associates with coronary artery disease rather than carotid lesions in patients with familial hypercholesterolemia. J Clin Lab Anal. 2018;32:e22442.

13. Jin JL, Cao YX, Wu LG, You XD, Guo YL, Wu NQ, Zhu CG, Gao Y, Dong QT, Zhang HW, et al. Triglyceride glucose index for predicting cardiovascular outcomes in patients with coronary artery disease. J Thoracic Dis. 2018;10: $6137-46$.

14. Zhang HW, Zhao X, Guo YL, Zhu CG, Wu NQ, Sun J, Liu G, Dong Q, Li JJ. Free fatty acids and cardiovascular outcome: a Chinese cohort study on stable coronary artery disease. Nutr Metab. 2017;14:41.

15. Liu HH, Cao YX, Li S, Guo YL, Zhu CG, Wu NQ, Gao Y, Dong QT, Zhao X, Zhang Y, et al. Impacts of Prediabetes Mellitus Alone or Plus Hypertension on the Coronary Severity and Cardiovascular Outcomes. Hypertension. 2018; 71:1039-46.

16. Gensini GG. A more meaningful scoring system for determining the severity of coronary heart disease. Am J Cardiol. 1983;51:606.
17. Cao YX, Jin JL, Sun D, Liu HH, Guo YL, Wu NQ, Xu RX, Zhu CG, Dong Q, Sun $J$, et al. Circulating PCSK9 and cardiovascular events in FH patients with standard lipid-lowering therapy. J Transl Med. 2019;17:367.

18. Crouse JR, Harpold GH, Kahl FR, Toole JF, McKinney WM. Evaluation of a scoring system for extracranial carotid atherosclerosis extent with B-mode ultrasound. Stroke. 1986;17:270-5.

19. Steinberg HO, Tarshoby M, Monestel R, Hook G, Cronin J, Johnson A, Bayazeed B, Baron AD. Elevated circulating free fatty acid levels impair endothelium-dependent vasodilation. J Clin Invest. 1997;100:1230-9.

20. Mathew M, Tay E, Cusi K. Elevated plasma free fatty acids increase cardiovascular risk by inducing plasma biomarkers of endothelial activation, myeloperoxidase and PAl-1 in healthy subjects. Cardiovasc Diabetol. 2010;9:9.

21. Lv ZH, Ma P, Luo W, Xiong H, Han L, Li SW, Zhou X, Tu JC. Association between serum free fatty acid levels and possible related factors in patients with type 2 diabetes mellitus and acute myocardial infarction. BMC Cardiovasc Disord. 2014;14:159.

22. Steinberg HO, Paradisi G, Hook G, Crowder K, Cronin J, Baron AD. Free fatty acid elevation impairs insulin-mediated vasodilation and nitric oxide production. Diabetes. 2000;49:1231-8.

23. Hufnagel B, Dworak M, Soufi M, Mester Z, Zhu Y, Schaefer JR, Klumpp S, Krieglstein J. Unsaturated fatty acids isolated from human lipoproteins activate protein phosphatase type 2 Cbeta and induce apoptosis in endothelial cells. Atherosclerosis. 2005;180:245-54.

24. Ghosh A, Gao L, Thakur A, Siu PM, Lai CWK. Role of free fatty acids in endothelial dysfunction. J Biomed Sci. 2017;24:50.

25. Semenkovich CF. Fatty acid metabolism and vascular disease. Trends Cardiovasc Med. 2004;14:72-6.

26. Gruzdeva O, Uchasova E, Dyleva Y, Belik E, Kashtalap V, Barbarash O. Relationship between free fatty acids, insulin resistance markers, and oxidized lipoproteins in myocardial infarction and acute left ventricular failure. Diabetes Metab Syndr Obes. 2013;6:103-11.

\section{Publisher's Note}

Springer Nature remains neutral with regard to jurisdictional claims in published maps and institutional affiliations.

Ready to submit your research? Choose BMC and benefit from:

- fast, convenient online submission

- thorough peer review by experienced researchers in your field

- rapid publication on acceptance

- support for research data, including large and complex data types

- gold Open Access which fosters wider collaboration and increased citations

- maximum visibility for your research: over $100 \mathrm{M}$ website views per year

At BMC, research is always in progress.

Learn more biomedcentral.com/submissions 